\title{
Hepatic purinergic signaling gene network expression and its relationship with inflammation and oxidative stress biomarkers in blood from peripartal dairy cattle
}

\author{
J. Seo, ${ }^{\star} †$ J. S. Osorio,† E. Schmitt,‡ M. N. Corrêa,§ G. Bertoni,\# E. Trevisi,\# and J. J. Loor† ${ }^{1}$ \\ *Department of Agricultural Biotechnology, Research Institute for Agriculture and Life Sciences, College of Agriculture and Life Sciences, \\ Seoul National University, Daehak-dong, Kwanak-gu, Seoul 151-742, Republic of Korea \\ †Mammalian NutriPhysioGenomics, Department of Animal Sciences, and Division of Nutritional Sciences, University of Illinois, \\ 1207 West Gregory Drive, Urbana 61801 \\ ‡Empresa Brasileira de Pesquisa Agropecuária (Embrapa), Rondônia, BR 364, Km 5.5, Zona Rural, Caixa Postal 127, CEP 76815-800, \\ Porto Velho, Rondônia, Brazil \\ §Universidade Federal de Pelotas, NUPEEC, Departamento Clínicas Veterinária, Campus Universitário, 96010-900, Pelotas, Rio Grande do Sul, \\ Brazil \\ \#lstituto di Zootecnica, Facoltà di Agraria, Università Cattolica del Sacro Cuore, 29122 Piacenza, Italy
}

\begin{abstract}
The liver plays a central role in allowing dairy cattle to make a successful transition into lactation. In liver, as in other tissues, extracellular nucleotides and nucleosides trigger cellular responses through adenosine and ATP receptors. Adenosine triphosphate and certain nucleotides serve as signals that can heighten purinergic receptor activation in several pathologic processes. We evaluated the mRNA expression of genes associated with the purinergic signaling network in liver tissue during the peripartal period. Seven multiparous Holstein cows were dried off at $d-50$ relative to expected parturition and fed a controlled-energy diet (net energy for lactation $=1.24 \mathrm{Mcal} / \mathrm{kg}$ of $\mathrm{DM}$ ) for ad libitum intake during the entire dry period. After calving, all cows were fed a common lactation diet (net energy for lactation $=1.65 \mathrm{Mcal} / \mathrm{kg}$ of $\mathrm{DM}$ ) until 30 DIM. Biopsies of liver were harvested at $\mathrm{d}-10,7$, and 21 for mRNA expression of 9 purinergic receptors, 7 ATP and adenosine transport channels, and 10 enzymes associated with ATP hydrolysis. Blood collected at $\mathrm{d}-21,-10,7,14$, and 21 was used to measure concentrations of inflammation and oxidative stress biomarkers. The expression of type 1 purinergic receptors (ADORA2A and ADORA3), several nucleoside hydrolases [ectonucleoside triphosphate diphosphohydrolase 7 (ENTPD 7 ), ectonucleotide pyrophosphatase/ phosphodiesterase 2 (ENPP2), ENPP3, and adenosine deaminase $(A D A)]$, and a type 2 purinergic receptor $\left(P 2 R X^{n}\right)$ was downregulated after calving. In contrast, the expression of type 2 purinergic receptors $\left(P 2 R X_{4}\right.$ and PR2Y11), an ATP release channel (gap junction
\end{abstract}

Received August 16, 2013

Accepted November 5, 2013.

${ }^{1}$ Corresponding author: jloor@illinois.edu hemichannel GJB1), and an adenosine uptake protein (SLC29A1) followed the opposite response, increasing after calving and remaining elevated through 21 d. Haptoglobin, ceruloplasmin, and reactive oxygen metabolite concentrations increased gradually from d $-21 \mathrm{~d}$ through at least $\mathrm{d} 7$. The opposite response was observed for albumin, paraoxonase, $\alpha$-tocopherol, and nitric oxide, which decreased gradually to a nadir at 7 and $14 \mathrm{~d}$. Our results suggest that alterations after calving of the expression of hepatic purinergic signaling genes could be functionally important because in nonruminants, they play roles in bile formation, glucose metabolism, cholesterol uptake, inflammation, and steatosis. The correlation analysis provided evidence of a link between purinergic signaling genes and biomarkers of inflammation and oxidative stress.

Key words: liver metabolism, transition cow, adenosine, adenosine triphosphate

\section{INTRODUCTION}

In the 1970s, the mechanism of purinergic signaling and the function of extracellular ATP as a signaling molecule were demonstrated by Burnstock (1972). Since then, work in nonruminants revealed that various metabolic tissues such as liver, adipose, and skeletal muscle express purinergic receptors and ATP-hydrolysis ectoenzymes (Fausther et al., 2012). The P1 (or ADORA) and P2 (or P2RX/Y) purinergic receptors are activated by extracellular nucleotides [e.g., ATP, adenosine diphosphate (ADP), uridine triphosphate uridine diphosphate (UTP), and (UDP)] and adenosine (also inosine) to modulate liver functions such as protein synthesis, cell proliferation, glucose metabolism, and immune responses (Beldi et al., 2008a). Besides their role within tissues, various nucleosides (e.g., adenosine, adenine, and 5-guanosine monophosphate) 
released by bacterial pathogens serve as signals to suppress components of the oxidative killing mechanisms of immune cells (e.g., neutrophils, macrophages; Canning et al., 1985, 1986).

The $\mathrm{P} 1$ receptors are classified as $\mathrm{A} 1$ (ADORA1), A2a (ADORA2A), A2b (ADORA2B), and A3 (ADORA3; Barletta et al., 2012). The P2 receptors are classified as ligand ion-gated channels (P2RX1 to $P 2 R X \eta)$ or G-protein coupled channels (P2RY1, P2RY2, P2RY4, $P 2 R Y 6$, and P2RY11 to P2RY14). The former modulate extracellular ion fluxes (e.g., $\mathrm{Na}^{+}, \mathrm{K}^{+}, \mathrm{Ca}^{2+}$, and $\mathrm{Cl}^{-}$) and the latter modulate cytosolic cyclic AMP (cAMP) concentration (Beldi et al., 2008a; Junger, 2008), glycogen phosphorylase activity, bile formation, cytokine secretion, and cholesterol metabolism (Fausther and Sévigny, 2011; Fausther et al., 2012).

Several mechanisms of cellular ATP release have been proposed thus far, including the gap junction (GJ) hemichannels (GJA1, GJB1, and GJB2), and pannexin 1 (PA NX1; Fausther and Sévigny, 2011). Once ATP is released from the cell, it is rapidly converted to ADP, AMP, adenosine, and inosine in a stepwise fashion (Fitz, 2007). Various nucleotide hydrolyzing enzymes take part in the extracellular ATP metabolism cycle, including several isotypes of ectonucleoside triphosphate diphosphohydrolase ( $\boldsymbol{E N T P D})$ and ectonucleotide pyrophosphatase/phosphodiesterase $(\boldsymbol{E N P P})$, ecto-5'-nucleotidase $(\boldsymbol{N T} \boldsymbol{5} \boldsymbol{E})$, and adenosine deaminase ( $\boldsymbol{A} \boldsymbol{D} \boldsymbol{A}$; Beldi et al., 2008b; Fausther and Sévigny, 2011; Junger, 2011). The ENTPD enzyme converts ATP or ADP to AMP, ENPP converts ATP to AMP, NT5E converts AMP to adenosine, and ADA converts adenosine to inosine. After ATP hydrolysis by ectonucleotidases and other nucleosidases, adenosine is transported into the cytosol primarily via the integral-membrane "equilibrative" nucleoside transporters (e.g., SLC29A1 and SLC29A2; Junger, 2011; Choi and Berdis, 2012).

Strong evidence exists in nonruminants that activation of purinergic receptors in cells of the liver can modulate specific functions, including bile secretion, glucose metabolism, cholesterol metabolism, and inflammation (Fausther and Sévigny, 2011). Furthermore, evidence exists that bacterial pathogens utilize nucleosides as one mechanism to inhibit the host immune response (Canning et al., 1985, 1986). The peripartal period in dairy cattle is characterized by a decrease in plasma cholesterol and glucose concentration along with increases in the concentrations of inflammatory indicators synthesized by the liver, all of which reflect alterations characteristic of the onset of lactation (Drackley et al., 2006; Bertoni et al., 2009). It is currently believed that metabolic stress and an altered immune function are causative factors leading to increased incidence of infectious diseases and chronic inflammatory events (Goff,
2006; Bionaz et al., 2007; Bertoni et al., 2008; Sordillo et al., 2009). However, the cause (or causes) of the socalled immunosuppression (Mallard et al., 1998) around the time of calving is not completely understood.

Alterations in the synthesis of nucleosides or the mRNA expression of purinergic signaling genes, or both, could contribute to metabolic stress and immunosuppression around parturition. For instance, the mRNA expression of $A D A$ and PANX1 (a nucleotide release channel) in blood neutrophils increased almost 2 -fold between -10 and $3 \mathrm{~d}$ around calving (Seo et al., 2013), suggesting an increase in the local concentration of nucleotides and nucleosides. To our knowledge, no information is available on the plasticity of purinergic signaling gene networks in the liver around parturition. Therefore, our main objective was to evaluate the expression profiles of the purinergic signaling gene network in the liver. Profiles in blood of several indicators of oxidative stress and inflammation also were analyzed.

\section{MATERIALS AND METHODS}

\section{Animals and Management}

Complete details of these procedures were previously reported by Ji et al. (2012). Briefly, 7 multiparous Holstein cows were used. All cows were dried off at d -50 relative to expected parturition and fed a controlledenergy diet $\left(\mathrm{NE}_{\mathrm{L}}=1.24 \mathrm{Mcal} / \mathrm{kg}\right.$ of $\left.\mathrm{DM}\right)$ containing wheat straw at $36 \%$ of DM for ad libitum intake for the entire dry period. After calving, all cows were fed a common lactation $\operatorname{diet}\left(\mathrm{NE}_{\mathrm{L}}=1.65 \mathrm{Mcal} / \mathrm{kg}\right.$ of $\left.\mathrm{DM}\right)$ until 30 DIM.

\section{Liver Biopsy}

Liver was sampled via puncture biopsy from cows under local anesthesia at approximately $0700 \mathrm{~h}$ on $\mathrm{d}$ $-10,7$, and 21 relative to parturition, following procedures described previously (Graugnard et al., 2013). Tissue samples were snap-frozen immediately in liquid $\mathrm{N}$ and transferred to a $-80^{\circ} \mathrm{C}$ freezer for storage until analyses of lipid composition (Ji et al., 2012) and RNA extraction.

\section{Blood Biomarkers}

Blood was sampled from the coccygeal vein every Monday and Thursday before the morning feeding from d -26 to 30 relative to parturition. Samples were collected into evacuated tubes containing Li-heparin or clot activator (BD Vacutainer; BD and Co., Franklin Lakes, NJ). Plasma and serum were obtained by cen- 
trifugation at $1,900 \times g$ for $15 \mathrm{~min}$ at $4^{\circ} \mathrm{C}$ and frozen at $-20^{\circ} \mathrm{C}$ until later analysis. In accordance with the methods described by Bionaz et al. (2007), samples were used to determine (a) inflammatory response indices: positive acute-phase proteins (+ APP; haptoglobin and ceruloplasmin) and negative acute-phase proteins (-APP; albumin and cholesterol, as an index of lipoproteins); (b) oxidative stress and related compounds: total reactive oxygen metabolites (ROM), total nitric oxide (NO) metabolites, and paraoxonase $(\mathbf{P O N})$; and (c) vitamins: $\alpha$-tocopherol and $\beta$-carotene. Also, total antioxidants were assessed through the oxygen radical absorbance capacity (ORAC) assay. This method measures a fluorescent signal from a probe (fluorescein) that decreases in the presence of radical damage (Cao and Prior, 1999). The analysis was performed with a multi-detection microplate reader equipped with a dual reagent injector (BioTek Synergy 2; BioTek Instruments Inc., Winooski, VT). Serum amyloid A (SAA) concentration was assessed with a commercial ELISA immunoassay kit (Tridelta Development Ltd., Manynooth, Co. Kildare, Ireland).

\section{Reverse-Transcription Quantitative PCR}

Specific details of RNA isolation from liver tissue, primer design, evaluation, and real-time quantitative PCR (qPCR) are presented in the Supplemental Materials (available online at http://dx.doi.org/10.3168/ jds.2013-7379). Details of primer product sequencing results, primer sequence and amplicon size, and qPCR performance are reported in Supplemental Tables S1, $\mathrm{S} 2$, S3, and $\mathrm{S} 4$. We used GAPDH, ribosomal protein S9 (RPS9), and ubiquitously expressed transcript (UXT) as internal control genes. Target genes were normalized with the geometric mean of these internal control genes (Table 1 and Figures 3, 4, and 5). Percentage relative abundance of mRNA (Supplemental Figure S1, available online at http://dx.doi.org/10.3168/jds.20137379) was calculated to provide additional mechanistic information on the target genes (Bionaz and Loor, 2008).

\section{Statistical Analysis}

The data of gene expression and blood biomarkers were analyzed with PROC MIXED of SAS (version 9.2; SAS Institute Inc., Cary, NC). The fixed effect in the model was parity, time, and parity $\times$ time. The random effect was cow. Upon analysis, it was determined that parity was only significant for albumin and cholesterol; thus, this term was removed from other models. Unequally spaced data were analyzed using the exponential correlation covariance structure SP for repeated measures. Least squares means separation between time points was performed using the PDIFF statement. Correlation analysis between blood biomarkers and gene expression data was performed using PROC CORR of SAS. Significance was declared at $P<0.05$.

\section{RESULTS}

\section{Inflammation Markers in Blood}

Except for SAA $(P=0.19$; Figure 1$)$, all inflammation markers had a significant time effect $(P<0.05)$. A parity effect was observed for albumin $(P=0.05)$ and cholesterol $(P=0.05)$ only. The concentration of haptoglobin and ceruloplasmin experienced a gradual increase $(P<0.05)$ between $\mathrm{d}-21$ through at least $\mathrm{d}$ 7 around calving, at which point a nadir in concentration was observed, namely for albumin, when compared with d -21 (Figure 1). Unlike haptoglobin, however, the concentration of ceruloplasmin remained elevated $(P<0.05)$ at 7 through $21 \mathrm{~d}$ compared with the prepartal time points. Although not significant, SAA concentration increased ca. 2.3 -fold (24.6 vs. $55.7 \mu \mathrm{g} / \mathrm{mL}$ ) from $\mathrm{d}-21$ to 7 , which followed a similar pattern as haptoglobin and ceruloplasmin. The opposite response was observed for the concentration of albumin, which decreased $(P<0.009)$ gradually to a nadir at $\mathrm{d} 7$ and 14 (Figure 1). Similarly, cholesterol concentration decreased $(P<0.001)$ during the transition period, with nadir levels at $\mathrm{d}-10$ and 7 . The latter was followed by a marked increase $(P<0.001)$ from d 7 to 21 , at which point it reached the highest concentration (Figure 1).

\section{Oxidant and Antioxidant Markers in Blood}

Concentration of ROM, PON, $\beta$-carotene, $\alpha$-tocopherol, and the measurement of ORAC had a time effect $(P<0.009)$, whereas no parity effect $(P$ $>0.05$ ) was observed for these parameters (Figure $2)$. The concentration of ROM increased $(P<0.05)$ gradually from d -21 to peak values at $\mathrm{d} 7$ and 14 , followed by a return to prepartal concentrations on $\mathrm{d}$ 21 (Figure 2). The opposite response was observed for the concentration of PON, $\alpha$-tocopherol, and NO, all of which decreased $(P<0.05)$ gradually from $\mathrm{d}-21$ to lower concentrations at $\mathrm{d} 7$ and 14 , followed by a return to prepartal $(\mathrm{d}-10)$ concentrations by $\mathrm{d} 21$. In contrast to PON and $\alpha$-tocopherol, with the exception of a sharp decreased at $\mathrm{d} 14(P<0.009), \beta$-carotene remained unchanged throughout the peripartal period. The measurement of ORAC was unchanged $(P>0.05)$ at $\mathrm{d}-21$ through 7 but then increased $(P<0.05)$ markedly by d 14 and 21, at which point the highest capacity was observed. 

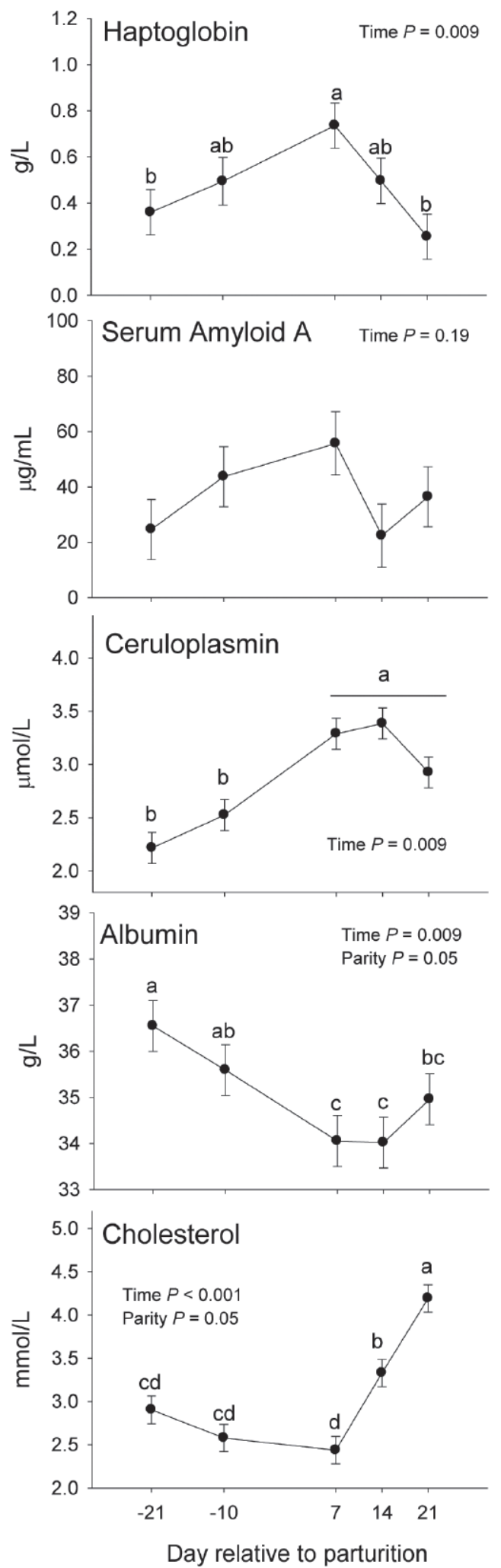

Figure 1. Profiles of positive acute-phase proteins (haptoglobin, serum amyloid A, and ceruloplasmin), a negative acute-phase protein (albumin), and cholesterol in blood during the peripartal period. Different letters $(\mathrm{a}-\mathrm{d})$ indicate differences between time points $(P<$ 0.05). Error bars represent the SEM.

\section{Purinergic Receptors}

With the exception of P2RY8 $(P=0.12$; Table 1$)$, all genes related to purinergic receptors had a significant time effect $(P<0.04)$. The expression of P2RY13, $A D O R A 3$, and $P 2 R X^{r} 7$ decreased $(P<0.001)$ between $\mathrm{d}-10$ and 7 and remained lower than prepartum by $\mathrm{d}$ $21(P<0.001 ;$ Figure 3). In contrast, the expression of P2RY1 and P2RX4 increased $(P<0.001)$ between $\mathrm{d}-10$ and 7 ; however, by $\mathrm{d} 21$, expression of $P 2 R Y 1$ remained unchanged and $P 2 R X 4$ decreased $(P<0.01)$ and did not reach prepartal levels. Similar to P2RY13 and ADORA3, P2RY11 and ADORA2A decreased ( $P$ $<0.01)$ between $\mathrm{d}-10$ and 7 ; however, their expression reached $(P>0.28)$ prepartal levels by d 21 (Figure $3)$. The expression of $P 2 R Y 2$ and $P 2 R Y 12$ remained unchanged between $\mathrm{d}-10$ and 7 , but decreased $(P<$ 0.01 ) by d 21 (Figure 3 ).

\section{ATP Release and Adenosine Absorption Channels}

The time effect was significant for GJA1, GJB1, SLC29A1, and SLC17A9. In contrast, GJB2, PANX1, and SLC29A2 expression was not affected by time (Table 1 and Figure 4). The expression of GJA1 decreased $(P=$ 0.01 ) between $\mathrm{d}-10$ and 7 and returned to prepartal levels by d 21 (Figure 4). In contrast, the expression of GJB1, SLC29A1, and SLC17A9 increased $(P<0.005)$ between d -10 and 7, but by d 21, GJB1 and SLC29A1 remained unchanged and $S L C 17 A 9$ decreased $(P=$ $0.05)$ but did not reach prepartal levels.

\section{Nucleosidases and Nucleotidases}

With the exception of ENTPD3 ( $P=0.15$; Table 1 and Figure 5), all genes related to nucleosidase and nucleotidase activity were affected $(P<0.05)$ by time. A similar overall decrease in the expression of ENTPD2, ENTPD \%, ENPP1, ENPP2, and ENPP3 from d -10 to $21(P<0.01$; Figure 5$)$ was observed, with ENPP1 and ENTPD2 having a similar $(P>0.09)$ expression at $\mathrm{d}$ 7 compared with d -10 and 21. Similar to ENPP1 and ENTPD2, expression of ENTPD8 was similar at d -10 and 7 , but decreased $(P<0.05)$ by d 21 . The highest $(P<0.001)$ expression of $N T 5 E$ was observed at d 7 compared with other time points, whereas expression of $A D A$ was lowest $(P<0.002)$ at d 7 . In contrast to ENTPD2 and ENTPD\%, ENTPD1 had the lowest ( $P$ $<0.07$ ) expression postpartum at $\mathrm{d} 7$ and returned to prepartal levels by d 21 .

\section{Correlations Among Purinergic Signaling Genes and Blood Biomarkers}

Among genes evaluated, the expression of P2RX4 had the greatest number of significant correlations $(P$ 
Table 1. Expression patterns of genes associated with adenosine signaling [P2 purinergic receptor Y8 (P2RY8)], ATP release [gap junction B2 (GJB2)], ATP transport [pannexin 1 (PANX1)], adenosine uptake [solute carrier family 29 (equilibrative nucleoside transporter), member 2 (SLC29A2)], and hydrolysis of ATP [ectonucleoside triphosphate diphosphohydrolase 3 (ENTPD3)] in liver tissue during the peripartal period

\begin{tabular}{|c|c|c|c|c|c|}
\hline \multirow[b]{2}{*}{ Gene } & \multicolumn{3}{|c|}{ Day relative to parturition } & \multirow[b]{2}{*}{ SEM } & \multirow[b]{2}{*}{$P$-value } \\
\hline & -10 & 7 & 21 & & \\
\hline$P 2 R Y 8$ & 0.9 & 0.92 & 1.06 & 0.05 & 0.12 \\
\hline GJB2 & 0.82 & 0.89 & 0.91 & 0.06 & 0.61 \\
\hline$P A N X 1$ & 0.99 & 1.00 & 1.02 & 0.02 & 0.67 \\
\hline SLC29A2 & 1.35 & 1.10 & 1.10 & 0.09 & 0.08 \\
\hline ENTPD3 & 0.99 & 1.12 & 1.06 & 0.10 & 0.15 \\
\hline
\end{tabular}

$<0.001$ ) with blood biomarkers (i.e., its expression was positively correlated with the concentration of ROM and ceruloplasmin and negatively correlated with $\mathrm{NO}$; Table 2). The concentration of NO also was negatively correlated with expression of P2RY1. The expression of $S L C 17 A 9$ was positively correlated with ROM concentration, but expression of $A D O R A 3$ and P2RX 7 was negatively correlated with ROM concentration. The expression of ENTPD 7 was positively correlated with PON concentration, but expression of ENTPD8 was negatively correlated with PON. The expression of PQRY2 was positively correlated with SAA concentration (Table 2).
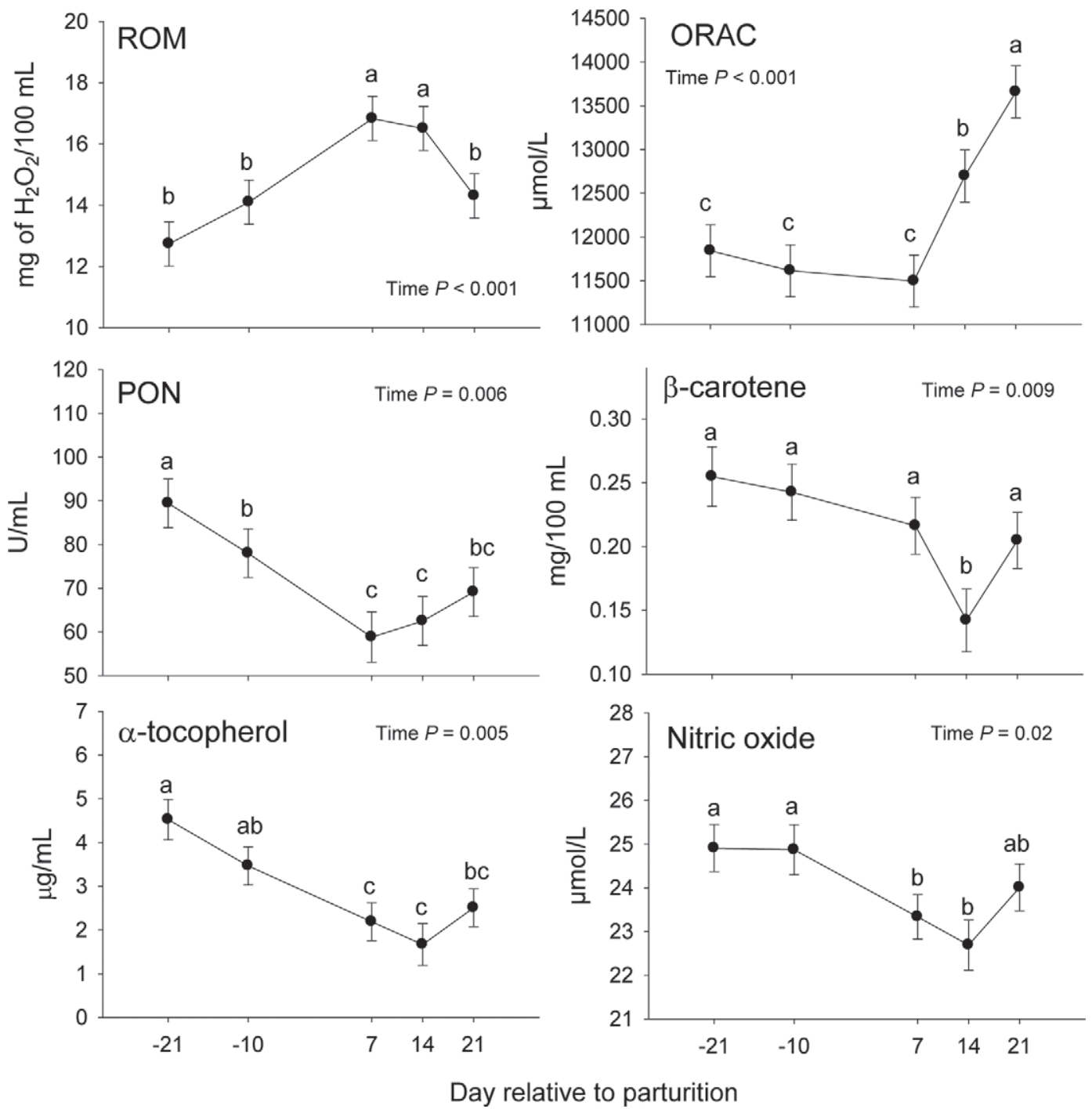

Figure 2. Profiles of oxidative stress markers [total reactive oxygen metabolites (ROM), oxygen radical absorbance capacity (ORAC), and paraoxonase $(\mathrm{PON})]$ and vitamins with antioxidant potential in blood during the peripartal period. Different letters (a-c) indicate differences between time points $(P<0.05)$. Error bars represent the SEM. 


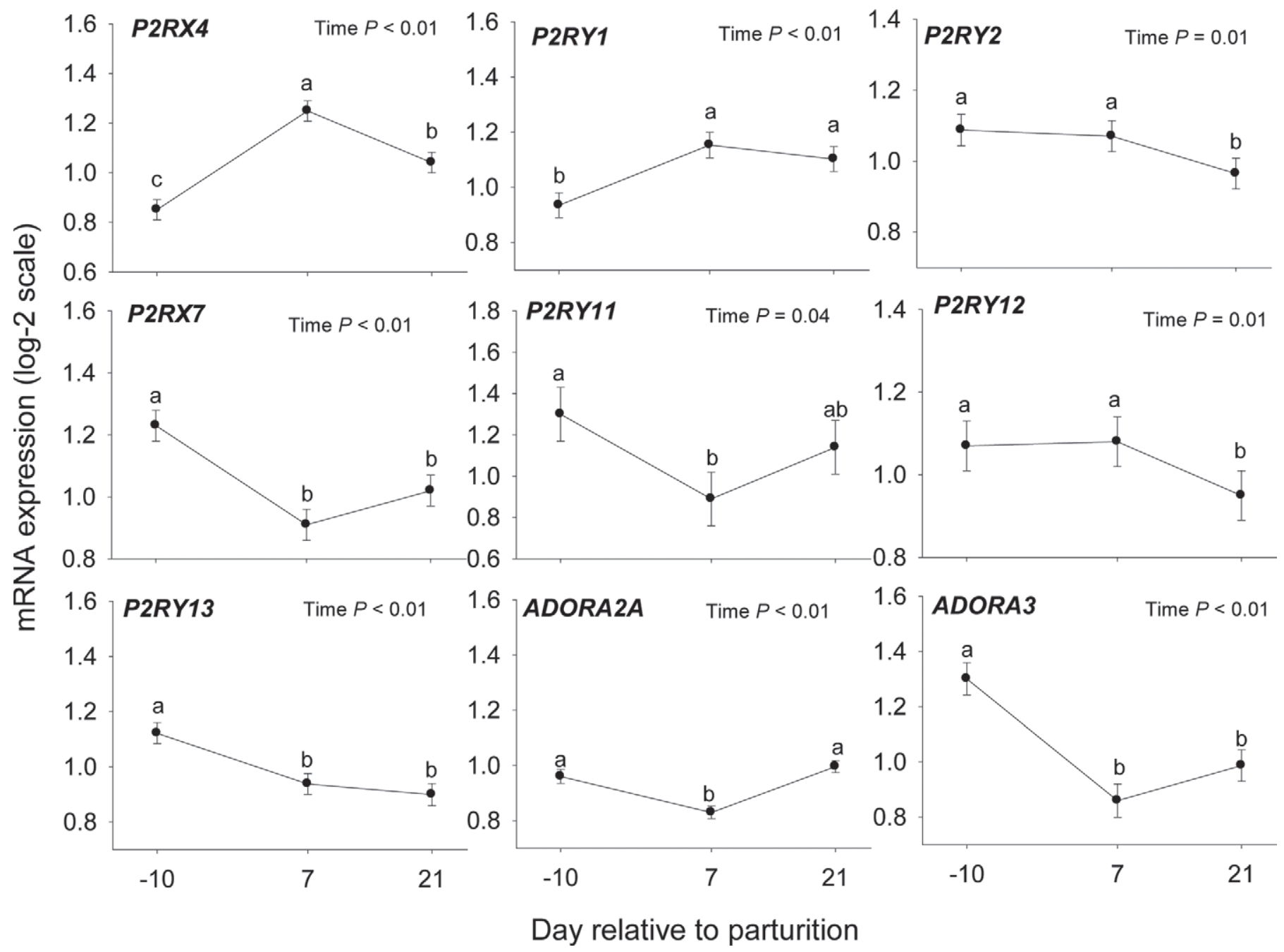

Figure 3. Expression profile of purinergic signaling genes and adenosine receptors in liver tissue during the peripartal period. Different letters $(\mathrm{a}-\mathrm{c})$ indicate differences between time points $(P<0.05)$. P2RX $/ Y=\mathrm{P} 2$ purinergic receptors; ADORA $=\mathrm{P} 1$ purinergic receptor. Error bars represent the SEM.

\section{DISCUSSION}

\section{Metabolism and Immune Function Around Calving}

A substantial body of published literature has provided evidence that metabolic stress (e.g., increases in blood NEFA and hydroxybutyrate concentrations coupled with lower glucose concentration) and an altered immune function are causative factors leading to greater incidence of infectious diseases and chronic inflammatory events (Kehrli and Goff, 1989; Bionaz et al., 2007; Sordillo et al., 2009). However, the cause (or causes) of the so-called immunosuppression (Mallard et al., 1998) around the time of calving is not completely understood.

Undoubtedly, the metabolic stress associated with the onset of lactation is one of the factors that affect both innate and adaptive immune function (Goff, 2006). For instance, negative energy balance around calving has been associated with diminished lymphocyte proliferation (Kehrli et al., 1989), decreased antibody concentrations (van Knegsel et al., 2007), and antibody responses (Mallard et al., 1997). It has to be emphasized, however, that the period of immune suppression begins as early as 2 to 3 wk before calving (Kehrli and Goff, 1989) when energy balance is still positive (Lacetera et al., 2005). Therefore, additional factors or a combination of factors (Kehrli and Goff, 1989) at the tissue, systemic, or immune cell level must be associated with the onset (and likely persistency) of immunosuppression.

From a metabolic standpoint, the role of the liver after calving is well established (Reynolds et al., 2003). The almost doubling in hepatic metabolic rate from 

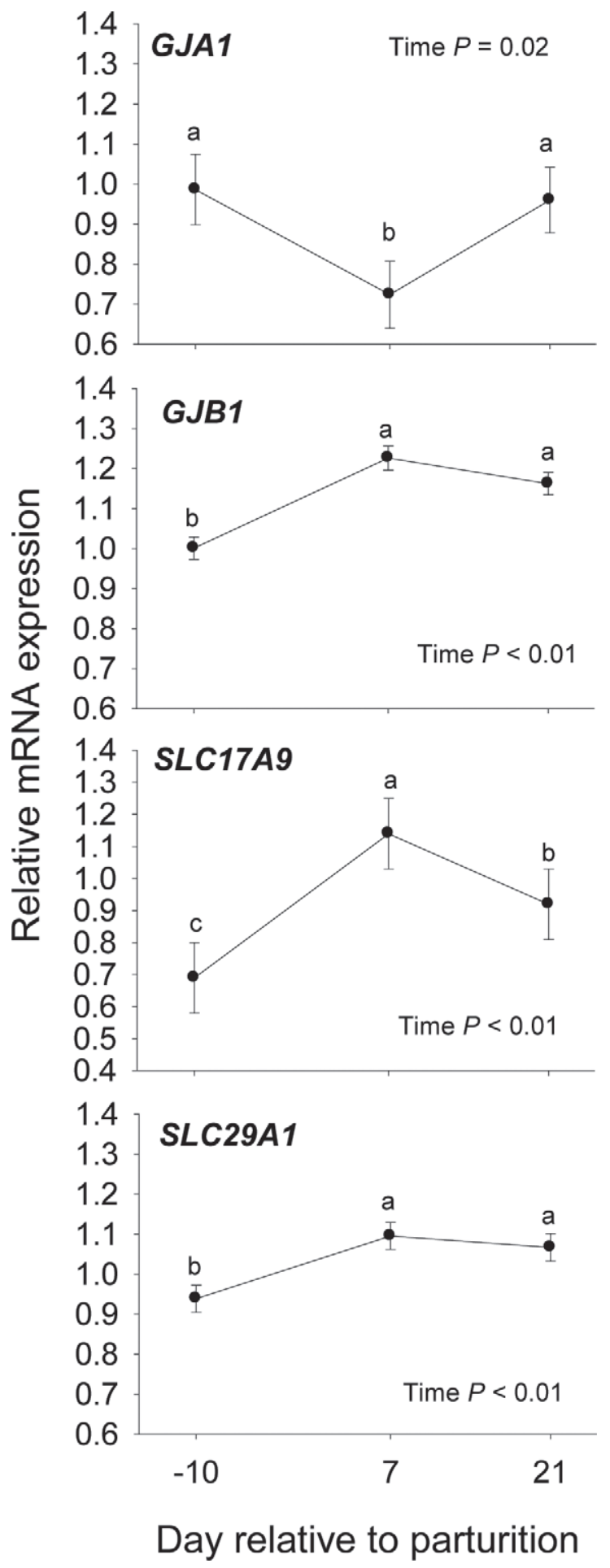

Figure 4. Expression profile of intercellular channels and a nucleoside transporter (SLC29A1) in liver tissue during the peripartal period. Different letters $(\mathrm{a}-\mathrm{c})$ indicate differences between time points $(P$ $<0.05) . G J=$ gap junction. Error bars represent the SEM.

late prepartum through early postpartum is driven primarily by the need to synthesize glucose for milk synthesis in the mammary gland (i.e., this tissue takes precedence in the use of glucose, hence, reducing the amounts available for immune cells as well as other key tissues such as adipose and skeletal muscle; Bell, 1995). More recent studies have revealed that liver also synthesizes and exports hepatokines (e.g., ANGPTL4 and FGF21; Loor et al., 2007; Schoenberg et al., 2011) that help coordinate the extrahepatic adaptations at the onset of lactation.

Although speculative, but based on nonruminant studies (Fausther and Sévigny, 2011), adaptations in purinergic signaling within the liver that might lead to changes in the intra and extracellular concentrations of nucleotides and nucleosides could play a functional role in coordinating hepatic functions associated with metabolism and immunity. Whether these signals alter the function of immune cells such as blood neutrophils or Kupffer cells is uncertain. The fact that neutrophil genes encoding proteins associated with synthesis and transport of nucleosides increased markedly after calving (Seo et al., 2013) suggests that these molecules have a mechanistic role in metabolic and immune adaptations to the onset of lactation.

\section{Peripartal Blood Biomarkers}

The increase in haptoglobin, ceruloplasmin, and SAA concentrations from prepartum $(\mathrm{d}-21)$ to early postpartum (d 7) was a sign of an acute-phase response as a consequence of common inflammatory conditions around calving (Bionaz et al., 2007). As expected, whereas hepatic production of the +APP markers (haptoglobin, ceruloplasmin, and SAA) increased during the peripartal period, the concentration of -APP markers, such as albumin and cholesterol, decreased. The changes in APP markers observed indicate that cows underwent significant metabolic and physiological challenges that are further confirmed by the postpartal response in blood ROM and ORAC. The sharp increase in ROM between $\mathrm{d}-10$ and 7, observed in previous studies (Trevisi et al., 2009; Grossi et al., 2013), reflects an increase in the oxidative stress as a result of imbalance between ROM production and the neutralizing capacity of antioxidant mechanisms such as glutathione peroxidase, $\beta$-carotene, and $\alpha$-tocopherol (Bernabucci et al., 2005). The level of ORAC lagged behind ROM until it increased at $14 \mathrm{~d}$ postpartum, followed by its highest level at $21 \mathrm{~d}$, at which point ROM concentration decreased to prepartal levels. Such adaptations suggest a compensatory effect of ORAC over ROM, namely an induction of the antioxidant systems (mainly enzymatic). In fact, the decrease in postpartal concentrations of $\beta$-carotene and $\alpha$-tocopherol through $14 \mathrm{~d}$ postpartum would help reduce the ORAC levels during this period. 


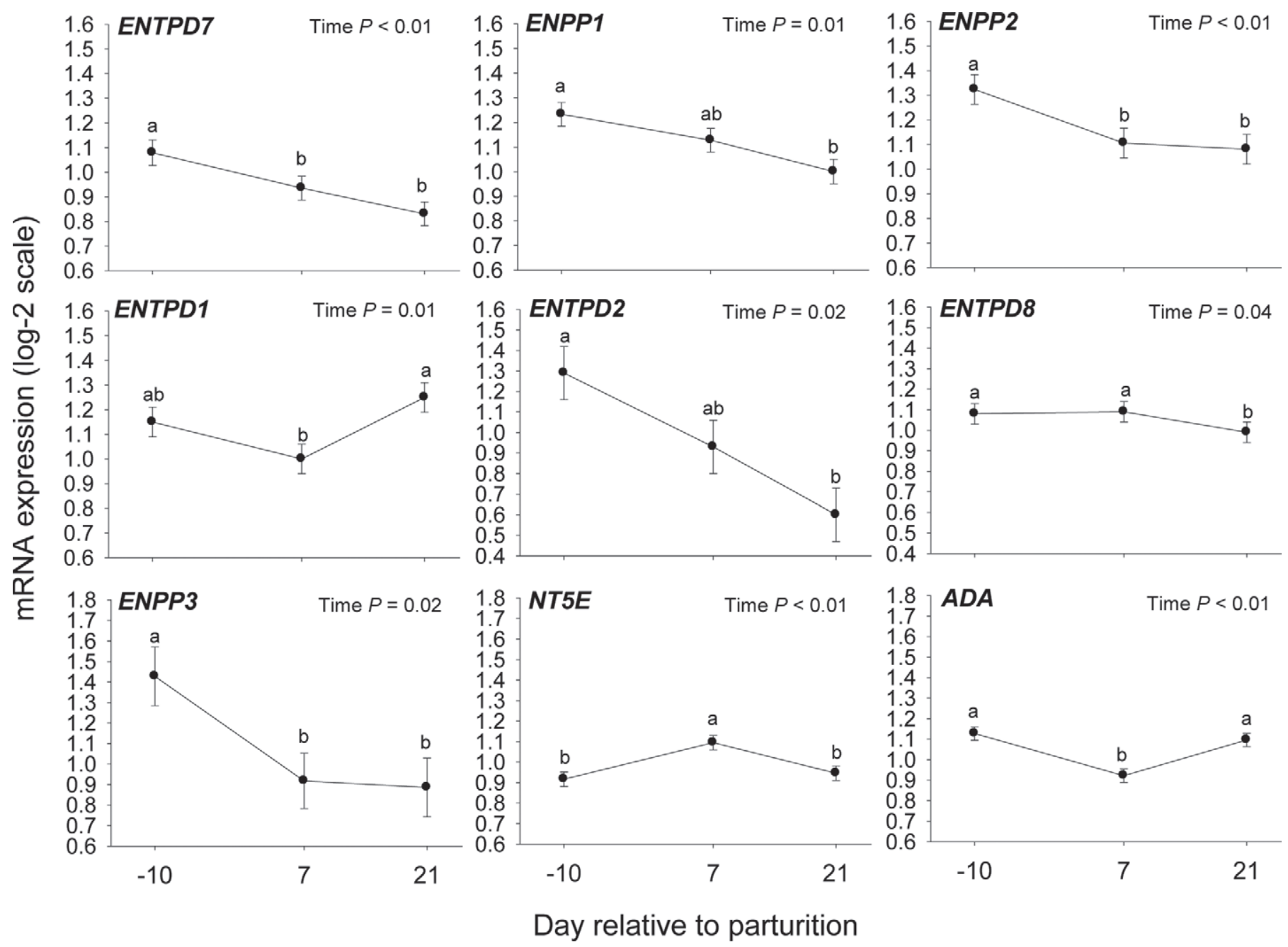

Figure 5. Expression profile of nucleotide esterases/hydrolases in liver tissue during the peripartal period. Different letters (a and b) indicate differences between time points $(P<0.05)$. ENTPD = ectonucleoside triphosphate diphosphohydrolase; $E N P P=$ ectonucleotide pyrophosphatase/phosphodiesterase; NT5E = ecto-5'-nucleotidase; $A D A=$ adenosine deaminase. Error bars represent the SEM.

Previous studies reported a negative correlation between oxidative stress and PON activity (Aviram and Rosenblat, 2004), which is consistent with the decrease in PON and the increase in ROM that we observed during the first $14 \mathrm{~d}$ postpartum. Besides oxidative stress, the decrease in PON concentration in plasma has been associated with liver damage and dysfunction due to excessive fat mobilization and triglyceride deposition in liver cells (Turk et al., 2004). Results similar to ours were reported previously by Bionaz et al. (2007) at calving time, but were attributed to inflammatory processes, which also increase the production of ROM and cause a deviation in the hepatic synthesis of APP [i.e., greater +APP and lower -APP (e.g., PON)].

\section{Purinergic Receptors}

Among the P2X and P2Y receptors we evaluated, P2RX4, P2RY1, and P2RY2 are known to take part in hepatocyte glucose metabolism (Dixon et al., 2004; Dixon et al., 2005; Emmett et al., 2008) and bile acid formation in nonruminants (Zsembery et al., 1998; Doctor et al., 2005; Woo et al., 2010). For instance, the culture of a P2X agonist (BzATP) in human and rat hepatocytes induced glucose release into medium by enhancing intracellular glycogenolysis (Emmett et al., 2008). In rat hepatocytes, the stimulation of $P 2 R Y 1$ via an agonist (2-methylthioadenosine 5 '-diphosphate) enhanced glycogen phosphorylase activity and increased cytosolic free $\mathrm{Ca}^{2+}$ concentration (Dixon et al., 2004). In a subsequent study, however, the same authors demonstrated, using human hepatocytes, that stimulation of P2RY2 via exogenous ATP had the same effects as P2RY1 in the rat model but also led to activation of the mitogen-activated protein kinase (MAPK) cascade (Dixon et al., 2005). Stimulation of the P2RY2 via exogenous ATP in a biliary cell line also led to greater 
$\mathrm{Na}^{+} / \mathrm{H}^{+}$ion-exchange activity and release of $\mathrm{HCO}_{3}$ into the medium (Zsembery et al., 1998).

The increase in expression of P2RX4 and P2RY1 after parturition might have been associated with glycogenolysis as a result of hypoglycemia, both of which are common adaptations to the onset of lactation (Drackley et al., 2006; Ingvartsen, 2006). In addition, although no data exist with peripartal cows, a recent study reported that an acute feed restriction of mid-lactation cows resulted in an overall inhibition of the MAPK signaling cascade (Akbar et al., 2013). Whether such response would occur in peripartal cows and be mechanistically related to P2RY2 expression/function remains to be elucidated. However, the fact that cows reduce their voluntary feed intake soon after calving would suggest that MAPK signaling also might be reduced.

A physiologically important outcome of reduced MAPK signaling is the fact that the MAPK pathway is involved in the regulation of steroid production via mechanisms including the induction of the low-density lipoprotein receptor, which is essential for the uptake of cholesterol by the liver (Singh et al., 1999). The fact that cholesterol concentration during the transition period decreases markedly (Bionaz et al., 2007; Bertoni et al., 2009; Graugnard et al., 2013) suggests a functional link with the MAPK pathway. As such, the MAPK cascade could play an important role in regulating cholesterol homeostasis as it does in nonruminants (Go and Mani, 2012). The positive correlation between expression of $P_{2} 2 X_{4}$ and $P 2 R Y 2$ and markers of inflammation and oxidative stress (ROM, ceruloplasmin, and SAA) also suggests a biological link. We are unaware of such links for these purinergic receptors in other mammalian systems.

Both P2RXY and P2RY11 appear to play a role in the process of inflammation. For instance, a recent study demonstrated that $P 2 R X Y$-null mice infected with Toxoplasma gondii experienced higher weight loss and had greater pathogen numbers as well as impaired liver function than wild-type mice with a fully functional P2RXY (Miller et al., 2011). That study also revealed that the absence of $P 2 R X Y$ delayed the production of the antiinflammatory cytokine IL-10, thus, leading to dysregulation of inflammation (Miller et al., 2011). The decrease in $P 2 R X^{\eta}$ after calving suggests that the antiinflammatory function of IL-10 might have been reduced.

Considering that one key role of P2RX7 is to enhance the antiinflammatory response (Miller et al., 2011), it is possible that the negative correlation between $P 2 R X^{\eta}$ and ROM reflects a negative effect of oxidative stress on this gene (i.e., a mechanism whereby oxidative stress augments inflammation). However, it should be kept in mind that the greater concentration of NO before
Table 2. Highest and lowest significant $(P<0.001)$ Pearson correlations among mRNA expression in liver tissue and blood biomarkers of inflammation, antioxidants, and oxidative stress during the transition period

\begin{tabular}{lll}
\hline Blood biomarker $^{1}$ & Gene $^{2}$ & $\mathrm{r}$ \\
\hline Positive correlations & & \\
Ceruloplasmin & P2RX4 & 0.66 \\
ROM & P2RX4 & 0.63 \\
ROM & SLC17A9 & 0.62 \\
PON & ENTPD & 0.59 \\
SAA & P2RY2 & 0.52 \\
Negative correlations & & \\
PON & ENTPD8 & -0.51 \\
NO & P2RX4 & -0.57 \\
ROM & ADORA3 & -0.58 \\
ROM & P2RX7 & -0.74 \\
NO & P2RY1 & -0.75 \\
\hline
\end{tabular}

${ }^{1} \mathrm{ROM}=$ total reactive oxygen metabolites; $\mathrm{PON}=$ paraoxonase; $\mathrm{SAA}$ $=$ serum amyloid $\mathrm{A} ; \mathrm{NO}=$ nitric oxide metabolites.

${ }^{2} P 2 R X / Y=\mathrm{P} 2$ purinergic receptors; SLC17A9 = solute carrier family 17 (vesicular nucleotide transporter), member $9 ; E N T P D=$ ectonucleoside triphosphate diphosphohydrolase; ADORA3 = adenosine A3 receptor.

calving (probably of placental origin) could be related to a mechanism to control (i.e., diminish) uterine contractions (Ticconi et al., 1996). Under such a scenario, the decrease in NO observed postpartum might be a normal consequence of delivery without being related with inflammatory or oxidative stress process.

The decrease in albumin observed after parturition coupled with the higher concentrations of haptoglobin, SAA, and ceruloplasmin clearly underscored the role of the liver in mounting an inflammatory response. However, it remains to be established if the intra- and extracellular concentrations of ATP in liver can have a mechanistic role in the local inflammatory response. It is tempting to speculate that because of the almost doubling of hepatic metabolic rate in liver after calving (Reynolds et al., 2003) and the increase in hepatocyte damage suggested by the increase in blood concentration of certain hepatic enzymes (Bertoni et al., 2008; Trevisi et al., 2009), local changes in concentration of ATP or the variation in expression of purinergic receptor expression, or both, might be a cause of inflammation.

Among the P2RY receptors, the expression of P2RY11 and P2RY13 were the only ones that decreased after parturition. The percentage abundance of $P 2 R Y 13$ was substantially greater than P2RY11 (Supplemental Figure S1, available online at http://dx.doi.org/10.3168/ jds.2013-7379), which might be biologically relevant because even though both receptors are highly sensitive to ATP, the activation of both receptors increases cytosolic $\mathrm{Ca}^{2+}$ but P2RY11 increases cAMP and P2RY13 decreases it (Yu et al., 2009). Other in vitro work with bile duct epithelial cells demonstrated that signaling via 
P2RY11 was necessary for extracellular ATP to stimulate an upregulation of $I L-6 \mathrm{mRNA}$ expression (Yu et al., 2009). The negative effect of blocking P2RY11 signaling on $I L-6$ mRNA expression could be partly reversed when the concentration of ATP in the culture was increased. Therefore, despite the downregulation of P2RY11 observed after calving, a greater cellular concentration of ATP due to hepatic metabolism might still have contributed to a proinflammatory response.

Other work with nonruminants has provided evidence that extracellular ADP also stimulates the expression of P2RY13, resulting in hepatic high-density lipoprotein (HDL) uptake via endocytosis (Jacquet et al., 2005), hence, potentially playing a role in reverse cholesterol transport in liver. Such a role was reinforced in a study demonstrating that P2RY13-null mice had reduced hepatic HDL uptake, hepatic cholesterol concentration, and cholesterol concentration in bile (Fabre et al., 2010). Assuming that extracellular ADP is a biologically relevant trigger, the recognition that ectoATP synthase in the hepatocyte cell surface is key for interacting with apolipoprotein A-1 and allowing for HDL endocytosis (Martinez et al., 2003) provides additional evidence that extracellular ADP activation of P2RY13 is an important trigger for induction of HDL endocytosis. The fact that the HDL fraction in plasma increases after calving and remains elevated during early lactation (Bernabucci et al., 2004) agrees with the gradual decrease in expression of P2RY13. In our study, the extracellular ADP concentration in the liver milieu might not have changed because the expression of ENTPD, which convert ATP to ADP, did not differ (ENTPD3) or actually decreased (ENTPD1, 2, 7, and 8) after parturition, therefore explaining, at least in part, the decrease in P2RY13 mRNA expression postcalving.

In rat liver, the signaling through ADORA2A helps suppress inflammation by inhibiting the expression of TNF, CXCL2, ICAM1, and the activating of nuclear factor $\kappa \mathrm{B}$ (Tang et al., 2010). Specific chemical agonists of ADORA2A can downregulate proinflammatory cytokine and chemokine mRNA expression (Day et al., 2004). The absence of ADORA3 also induced an acute proinflammatory response (e.g., increased TNF mRNA expression) during sepsis in mice (Lee et al., 2006). Compared with wild-type mice, ADORA2A-deficient mice had an increase in expression of TLR-associated proinflammatory cytokines and nuclear factor $\kappa \mathrm{B}(\mathrm{Lu}-$ kashev et al., 2004). In addition to their antiinflammatory role, ADORA2A and ADORA3 appear to play a role in hepatic glucose metabolism. An agonist specific for ADORA2A stimulated gluconeogenesis by increasing cAMP production in rat liver (González-Benítez et al., 2002). Similarly, Guinzberg et al. (2006) reported that ADORA3 stimulation by inosine and other agonists increased the rate of gluconeogenesis and glycogenolysis by elevating intracellular $\mathrm{Ca}^{2+}$ concentrations in rat hepatocytes. Overall, it would appear given their dual functions that signaling via ADORA2A and ADORA3 could serve as a mechanism to enhance the efficiency of energy utilization.

The downregulation of ADORA2A and ADORA3 coupled with the upregulation of $P_{2} 2 R X_{4}$ and P2RY1 after calving suggests that the extracellular ratio of ATP:ADP might have been greater and the inosine concentration lower. Once outside the cell, ATP has a half-life measured in seconds, as a result of the action of several nucleosidases, nucleotidases, and other hydrolytic enzymes causing the degradation of ATP to ADP, AMP, and adenosine (Picher et al., 2004). In mice, a null mutation of NT5E leads to a substantial decrease in extracellular adenosine concentration and hepatic injury upon an ischemic challenge (Hart et al., 2008). Conversion of adenosine to inosine relies on activity of $A D A$, subsequently leading to activation of ADORA3 (Franco et al., 1998; Cristalli et al., 2001). The extracellular concentrations of these nucleotides were not measured in our experiment. However, the lower postpartal expression of nucleosidases and nucleotidases $(E N T P D, E N P P)$ needed to produce adenosine from ATP coupled with lower expression of $A D A$ and the higher expression of the ATP-release channel (GJB1), the adenosine reuptake channel (SLC29A1), and NT5E are suggestive of a multifactorial mechanism regulating the relative concentration of these nucleotides. Furthermore, it could be possible that some of these nucleosidases (ENTPD1, 2, 3, 7, and 8) and nucleotidases (ENPP1, 2, and 3) are more responsive to a particular nucleotide.

To support a role of extracellular nucleotides on liver metabolism and function, it might be necessary to measure tissue concentrations of ATP, ADP, and even adenosine and inosine. However, our hypothesis is not hard to fathom because the rate of oxidative metabolism in the liver soon after calving increases markedly (Reynolds et al., 2003) and we observed an increase in postpartal ROM concentration. The fact that SLC29A1 had the greatest relative percentage mRNA abundance (accounted for approximately $45 \%$ of total genes analyzed; Supplemental Figure S1, available online at http://dx.doi.org/10.3168/jds.2013-7379), and assuming this effect would be the same at the protein level, suggests that cellular uptake of nucleotides across cellular and mitochondrial membranes is a biologically important response to the greater rates of oxidative metabolism in the liver after calving. An in vitro study 
demonstrated that greater expression of SLC29A1 was associated with greater cellular proliferation (Plotnik et al., 2012), a process that likely accounts, at least in part, for the increase in liver mass between pre- and postpartum (Reynolds et al., 2004). It also could be possible that the hepatic inflammation observed after calving plays a certain role in the increase in liver mass. The parallel increase in the concentration of inflammatory and oxidative stress markers from late prepartum through early lactation also seems to support a functional link among these purinergic receptors and inflammation and stress.

\section{CONCLUSIONS}

Our combined results indicate that it could be useful to investigate in more detail the likely reasons for the reduction of the purinergic receptors after calving and, in particular, if this is a consequence of the damage of the membranes (and consequent marked increase of extracellular ATP) or a physiological adaptation. It is now evident that local and systemic inflammatory signals characterizing the early postpartal period have an important effect on liver functionality.

\section{ACKNOWLEDGMENTS}

This research was supported by Hatch funds under project ILLU-538-392 (National Institute of Food and Agriculture, Washington, DC).

\section{REFERENCES}

Akbar, H., M. Bionaz, D. B. Carlson, S. L. Rodriguez-Zas, R. E. Everts, H. A. Lewin, J. K. Drackley, and J. J. Loor. 2013. Feed restriction, but not L-carnitine infusion, alters the liver transcriptome by inhibiting sterol synthesis and mitochondrial oxidative phosphorylation and increasing gluconeogenesis in mid-lactation dairy cows. J. Dairy Sci. 96:2201-2213.

Aviram, M., and M. Rosenblat. 2004. Paraoxonases 1, 2, and 3, oxidative stress, and macrophage foam cell formation during atherosclerosis development. Free Radic. Biol. Med. 37:1304-1316.

Barletta, K. E., K. Ley, and B. Mehrad. 2012. Regulation of neutrophil function by adenosine. Arterioscler. Thromb. Vasc. Biol. 32:856-864.

Beldi, G., K. Enjyoji, Y. Wu, L. Miller, Y. Banz, X. Sun, and S. C. Robson. 2008a. The role of purinergic signaling in the liver and in transplantation: Effects of extracellular nucleotides on hepatic graft vascular injury, rejection and metabolism. Front. Biosci. $13: 2588-2603$.

Beldi, G., Y. Wu, X. Sun, M. Imai, K. Enjyoji, E. Csizmadia, D. Candinas, L. Erb, and S. C. Robson. 2008b. Regulated catalysis of extracellular nucleotides by vascular CD39/ENTPD1 is required for liver regeneration. Gastroenterology 135:1751-1760.

Bell, A. W. 1995. Regulation of organic nutrient metabolism during transition from late pregnancy to early lactation. J. Anim. Sci. 73:2804-2819.

Bernabucci, U., B. Ronchi, L. Basiricò, D. Pirazzi, F. Rueca, N. Lacetera, and A. Nardone. 2004. Abundance of mRNA of apolipoprotein $\mathrm{B}_{100}$, apolipoprotein $\mathrm{E}$, and microsomal triglyceride trans- fer protein in liver from periparturient dairy cows. J. Dairy Sci. $87: 2881-2888$.

Bernabucci, U., B. Ronchi, N. Lacetera, and A. Nardone. 2005. Influence of body condition score on relationships between metabolic status and oxidative stress in periparturient dairy cows. J. Dairy Sci. 88:2017-2026.

Bertoni, G., E. Trevisi, X. Han, and M. Bionaz. 2008. Effects of inflammatory conditions on liver activity in puerperium period and consequences for performance in dairy cows. J. Dairy Sci. 91:3300-3310.

Bertoni, G., E. Trevisi, and R. Lombardelli. 2009. Some new aspects of nutrition, health conditions and fertility of intensively reared dairy cows. Ital. J. Anim. Sci. 8:491-518.

Bionaz, M., and J. J. Loor. 2008. Gene networks driving bovine milk fat synthesis during the lactation cycle. BMC Genomics 9:366.

Bionaz, M., E. Trevisi, L. Calamari, F. Librandi, A. Ferrari, and G. Bertoni. 2007. Plasma paraoxonase, health, inflammatory conditions, and liver function in transition dairy cows. J. Dairy Sci. 90:1740-1750.

Burnstock, G. 1972. Purinergic nerves. Pharmacol. Rev. 24:509-581.

Canning, P. C., J. A. Roth, and B. L. Deyoe. 1986. Release of 5'-guanosine monophosphate and adenine by Brucella abortus and their role in the intracellular survival of the bacteria. J. Infect. Dis. 154:464-470.

Canning, P. C., J. A. Roth, L. B. Tabatabai, and B. L. Deyoe. 1985. Isolation of components of Brucella abortus responsible for inhibition of function in bovine neutrophils. J. Infect. Dis. 152:913-921.

Cao, G., and R. L. Prior. 1999. Measurement of oxygen radical absorbance capacity in biological samples. Methods Enzymol. 299:5062.

Choi, J. S., and A. J. Berdis. 2012. Nucleoside transporters: Biological insights and therapeutic applications. Future Med. Chem. 4:1461-1478

Cristalli, G., S. Costanzi, C. Lambertucci, G. Lupidi, S. Vittori, R. Volpini, and E. Camaioni. 2001. Adenosine deaminase: Functional implications and different classes of inhibitors. Med. Res. Rev. $21: 105-128$.

Day, Y. J., M. A. Marshall, L. Huang, M. J. McDuffie, M. D. Okusa, and J. Linden. 2004. Protection from ischemic liver injury by activation of A2A adenosine receptors during reperfusion: Inhibition of chemokine induction. Am. J. Physiol. Gastrointest. Liver Physiol. 286:G285-G293.

Dixon, C. J., J. F. Hall, T. E. Webb, and M. R. Boarder. 2004. Regulation of rat hepatocyte function by $\mathrm{P} 2 \mathrm{Y}$ receptors: Focus on control of glycogen phosphorylase and cyclic AMP by 2-methylthioadenosine 5'-diphosphate. J. Pharmacol. Exp. Ther. 311:334-341.

Dixon, C. J., P. J. White, J. F. Hall, S. Kingston, and M. R. Boarder. 2005. Regulation of human hepatocytes by P2Y receptors: Control of glycogen phosphorylase, $\mathrm{Ca}^{2+}$, and mitogen-activated protein kinases. J. Pharmacol. Exp. Ther. 313:1305-1313.

Doctor, R. B., T. Matzakos, R. McWilliams, S. Johnson, A. P. Feranchak, and J. G. Fitz. 2005. Purinergic regulation of cholangiocyte secretion: Identification of a novel role for P2X receptors. Am. J. Physiol. Gastrointest. Liver Physiol. 288:G779-G786.

Drackley, J. K., S. S. Donkin, and C. K. Reynolds. 2006. Major advances in fundamental dairy cattle nutrition. J. Dairy Sci. 89:1324-1336.

Emmett, D. S., A. Feranchak, G. Kilic, L. Puljak, B. Miller, S. Dolovcak, R. McWilliams, R. B. Doctor, and J. G. Fitz. 2008. Characterization of ionotrophic purinergic receptors in hepatocytes. Hepatology 47:698-705.

Fabre, A. C., C. Malaval, A. Ben Addi, C. Verdier, V. Pons, N. Serhan, L. Lichtenstein, G. Combes, T. Huby, F. Briand, X. Collet, N. Nijstad, U. J. F. Tietge, B. Robaye, B. Perret, J.-M. Boeynaems, and L. O. Martinez. 2010. P2Y13 receptor is critical for reverse cholesterol transport. Hepatology 52:1477-1483.

Fausther, M., E. Gonzales, and J. A. Dranoff. 2012. Role of purinergic P2X receptors in the control of liver homeostasis. Wiley Interdiscip. Rev. Membr. Transp. Signal. 1:341-348. 
Fausther, M., and J. Sévigny. 2011. Les nucléosides et nucléotides extracellulaires régulent les fonctions hépatiques par le biais d'un système complexe de protéines membranaires. C. R. Biol. 334:100-117.

Fitz, J. G. 2007. Regulation of cellular ATP release. Trans. Am. Clin. Climatol. Assoc. 118:199-208.

Franco, R., A. Valenzuela, C. Lluis, and J. Blanco. 1998. Enzymatic and extraenzymatic role of ecto-adenosine deaminase in lymphocytes. Immunol. Rev. 161:27-42.

Go, G. W., and A. Mani. 2012. Low-density lipoprotein receptor (LDLR) family orchestrates cholesterol homeostasis. Yale J. Biol. Med. 85:19-28.

Goff, J. P. 2006. Major advances in our understanding of nutritional influences on bovine health. J. Dairy Sci. 89:1292-1301.

González-Benítez, E., R. Guinzberg, A. Díaz-Cruz, and E. Piña. 2002. Regulation of glycogen metabolism in hepatocytes through adenosine receptors. Role of $\mathrm{Ca}^{2+}$ and cAMP. Eur. J. Pharmacol. 437:105-111.

Graugnard, D. E., K. M. Moyes, E. Trevisi, M. J. Khan, D. Keisler, J. K. Drackley, G. Bertoni, and J. J. Loor. 2013. Liver lipid content and inflammometabolic indices in peripartal dairy cows are altered in response to prepartal energy intake and postpartal intramammary inflammatory challenge. J. Dairy Sci. 96:918-935.

Grossi, P., G. Bertoni, F. P. Piccioli Cappelli, and E. Trevisi. 2013. Effects of the precalving administration of omega-3 fatty acids alone or in combination with acetylsalicylic acid in periparturient dairy cows. J. Anim. Sci. 91:2657-2666.

Guinzberg, R., D. Cortés, A. Díaz-Cruz, H. Riveros-Rosas, R. Villalobos-Molina, and E. Piña. 2006. Inosine released after hypoxia activates hepatic glucose liberation through $\mathrm{A}_{3}$ adenosine receptors. Am. J. Physiol. Endocrinol. Metab. 290:E940-E951.

Hart, M. L., C. Much, I. C. Gorzolla, J. Schittenhelm, D. Kloor, G. L. Stahl, and H. K. Eltzschig. 2008. Extracellular adenosine production by ecto-5'-nucleotidase protects during murine hepatic ischemic preconditioning. Gastroenterology 135:1739-1750.

Ingvartsen, K. L. 2006. Feeding- and management-related diseases in the transition cow. Anim. Feed Sci. Technol. 126:175-213.

Jacquet, S., C. Malaval, L. O. Martinez, K. Sak, C. Rolland, C. Perez, M. Nauze, E. Champagne, F. Tercé, C. Gachet, B. Perret, X. Collet, J. M. Boeynaems, and R. Barbaras. 2005. The nucleotide receptor P2Y13 is a key regulator of hepatic high-density lipoprotein (HDL) endocytosis. Cell. Mol. Life Sci. 62:2508-2515.

Ji, P., J. S. Osorio, J. K. Drackley, and J. J. Loor. 2012. Overfeeding a moderate energy diet prepartum does not impair bovine subcutaneous adipose tissue insulin signal transduction and induces marked changes in peripartal gene network expression. J. Dairy Sci. 95:4333-4351.

Junger, W. G. 2008. Purinergic regulation of neutrophil chemotaxis. Cell. Mol. Life Sci. 65:2528-2540.

Junger, W. G. 2011. Immune cell regulation by autocrine purinergic signalling. Nat. Rev. Immunol. 11:201-212.

Kehrli, M. E., Jr., and J. P. Goff. 1989. Periparturient hypocalcemia in cows: Effects on peripheral blood neutrophil and lymphocyte function. J. Dairy Sci. 72:1188-1196.

Kehrli, M. E., Jr., B. J. Nonnecke, and J. A. Roth. 1989. Alterations in bovine lymphocyte function during the periparturient period. Am. J. Vet. Res. 50:215-220.

Lacetera, N., D. Scalia, U. Bernabucci, B. Ronchi, D. Pirazzi, and A. Nardone. 2005. Lymphocyte functions in overconditioned cows around parturition. J. Dairy Sci. 88:2010-2016.

Lee, H. T., M. Kim, J. D. Joo, G. Gallos, J.-F. Chen, and C. W. Emala. 2006. $\mathrm{A}_{3}$ adenosine receptor activation decreases mortality and renal and hepatic injury in murine septic peritonitis. Am. J. Physiol. Regul. Integr. Comp. Physiol. 291:R959-R969.

Loor, J. J., R. E. Everts, M. Bionaz, H. M. Dann, D. E. Morin, R. Oliveira, S. L. Rodriguez-Zas, J. K. Drackley, and H. A. Lewin. 2007. Nutrition-induced ketosis alters metabolic and signaling gene networks in liver of periparturient dairy cows. Physiol. Genomics 32:105-116.

Lukashev, D., A. Ohta, S. Apasov, J.-F. Chen, and M. Sitkovsky. 2004. Cutting edge: Physiologic attenuation of proinflammatory tran- scription by the $\mathrm{G}_{\mathrm{s}}$ protein-coupled $\mathrm{A} 2 \mathrm{~A}$ adenosine receptor in vivo. J. Immunol. 173:21-24.

Mallard, B. A., J. C. Dekkers, M. J. Ireland, K. E. Leslie, S. Sharif, C. L. Vankampen, L. Wagter, and B. N. Wilkie. 1998. Alteration in immune responsiveness during the peripartum period and its ramification on dairy cow and calf health. J. Dairy Sci. 81:585-595.

Mallard, B. A., L. C. Wagter, M. J. Ireland, and J. C. Dekkers. 1997. Effects of growth hormone, insulin-like growth factor-I, and cortisol on periparturient antibody response profiles of dairy cattle. Vet. Immunol. Immunopathol. 60:61-76.

Martinez, L. O., S. Jacquet, J.-P. Esteve, C. Rolland, E. Cabezón, E. Champagne, T. Pineau, V. Georgeaud, J. E. Walker, F. Tercé, X. Collet, B. Perret, and R. Barbaras. 2003. Ectopic $\beta$-chain of ATP synthase is an apolipoprotein A-I receptor in hepatic HDL endocytosis. Nature 421:75-79.

Miller, C. M., A. M. Zakrzewski, R. J. Ikin, N. R. Boulter, M. Katrib, M. P. Lees, S. J. Fuller, J. S. Wiley, and N. C. Smith. 2011 Dysregulation of the inflammatory response to the parasite, Toxoplasma gondii, in $\mathrm{P}_{2} \mathrm{X}_{7}$ receptor-deficient mice. Int. J. Parasitol. 41:301-308.

Picher, M., L. H. Burch, and R. C. Boucher. 2004. Metabolism of P2 receptor agonists in human airways: Implications for mucociliary clearance and cystic fibrosis. J. Biol. Chem. 279:20234-20241.

Plotnik, D. A., C. Asher, S. K. Chu, R. S. Miyaoka, G. G. Garwin, B W. Johnson, T. Li, K. A. Krohn, and J. L. Schwartz. 2012. Levels of human equilibrative nucleoside transporter-1 are higher in proliferating regions of A549 tumor cells grown as tumor xenografts in vivo. Nucl. Med. Biol. 39:1161-1166.

Reynolds, C. K., P. C. Aikman, B. Lupoli, D. J. Humphries, and D. E. Beever. 2003. Splanchnic metabolism of dairy cows during the transition from late gestation through early lactation. J. Dairy Sci. 86:1201-1217.

Reynolds, C. K., B. Durst, B. Lupoli, D. J. Humphries, and D. E. Beever. 2004. Visceral tissue mass and rumen volume in dairy cows during the transition from late gestation to early lactation. J. Dairy Sci. 87:961-971.

Schoenberg, K. M., S. L. Giesy, K. J. Harvatine, M. R. Waldron, C. Cheng, A. Kharitonenkov, and Y. R. Boisclair. 2011. Plasma FGF21 is elevated by the intense lipid mobilization of lactation. Endocrinology 152:4652-4661.

Seo, J., J. S. Osorio, and J. J. Loor. 2013. Purinergic signaling gene network expression in bovine polymorphonuclear neutrophils during the peripartal period. J. Dairy Sci. 96:7675-7683.

Singh, R. P., P. Dhawan, C. Golden, G. S. Kapoor, and K. D. Mehta. 1999. One-way cross-talk between p38 $8^{\mathrm{MAPK}}$ and $\mathrm{p} 42 / 44^{\mathrm{MAPK}}$ inhibition of $\mathrm{p} 38^{\mathrm{MAPK}}$ induces low density lipoprotein receptor expression through activation of the $\mathrm{p} 42 / 44^{\mathrm{MAPK}}$ cascade. J. Biol. Chem. 274:19593-19600

Sordillo, L. M., G. A. Contreras, and S. L. Aitken. 2009. Metabolic factors affecting the inflammatory response of periparturient dairy cows. Anim. Health Res. Rev. 10:53-63.

Tang, L.-M., J.-F. Zhu, F. Wang, J. Qian, J. Zhu, Q. Mo, H.-H. Lu, G.-Q. Li, and X.-H. Wang. 2010. Activation of adenosine A2A receptor attenuates inflammatory response in a rat model of smallfor-size liver transplantation. Transplant. Proc. 42:1915-1920.

Ticconi, C., A. Zicari, A. Losardo, G. Pontieri, N. Pasetto, and E. Piccione. 1996. Nitric oxide in human fetal membranes at term gestation: Effect on prostaglandin E2 release. Eur. J. Obstet. Gynecol. Reprod. Biol. 69:135-139.

Trevisi, E., M. Amadori, A. M. Bakudila, and G. Bertoni. 2009. Metabolic changes in dairy cows induced by oral, low-dose interferonalpha treatment. J. Anim. Sci. 87:3020-3029.

Turk, R., D. Juretic, D. Geres, N. Turk, B. Rekic, V. Simeon-Rudolf, and A. Svetina. 2004. Serum paraoxonase activity and lipid parameters in the early postpartum period of dairy cows. Res. Vet. Sci. 76:57-61.

van Knegsel, A. T., G. de Vries Reilingh, S. Meulenberg, H. van den Brand, J. Dijkstra, B. Kemp, and H. K. Parmentier. 2007. Natural antibodies related to energy balance in early lactation dairy cows. J. Dairy Sci. 90:5490-5498. 
Woo, K., M. Sathe, C. Kresge, V. Esser, Y. Ueno, J. Venter, S. S. Glaser, G. Alpini, and A. P. Feranchak. 2010. Adenosine triphosphate release and purinergic (P2) receptor-mediated secretion in small and large mouse cholangiocytes. Hepatology 52:1819-1828.

Yu, J., N. Sheung, E. M. Soliman, C. Spirli, and J. A. Dranoff. 2009 Transcriptional regulation of IL- 6 in bile duct epithelia by ex- tracellular ATP. Am. J. Physiol. Gastrointest. Liver Physiol. 296:G563-G571.

Zsembery, A., C. Spirli, A. Granato, N. F. LaRusso, L. Okolicsanyi, G. Crepaldi, and M. Strazzabosco. 1998. Purinergic regulation of acid/base transport in human and rat biliary epithelial cell lines. Hepatology 28:914-920. 